\title{
Art For Life: Race, Gender, Disability And Class - Critical Discourses Around Participation In Arts Education
}

Jeff Adams

A paradox that art educators often encounter in their work is that the arts, as they are recognised for their universal and inclusive values, may inadvertently reinforce elite and exclusive practices. Similarly, the development of pedagogies for critical approaches to culture has positively impacted on a broad and diverse range of learners in all phases of education, but the arts studio or classroom, this apparently democratic space for the production of learner and artefact, can also be a space that is governed by assessment regimes and educational conventions, and one which may also be characterised by reproduction, routine, and a reliance on entrenched pedagogic practices. Such are the ways in which current arts-based educational practices may on one hand enable and include, but on the other disable and exclude. Given this state of affairs, to what extent can arts education promote an inclusive participation in 'art for life', and in what ways does can it widen this participation?

These were the questions and issues that delegates from 16 countries at the 2013 IJADE/NSEAD research conference, held on the15th and 16th November 2013 at the University of Chester Research and Innovation Centre, assembled to explore. Part of the conference was staged at Liverpool Tate for the exhibition 'Art turning left: how values changed making 1789-2013' which included the work of Anni Albers, Walter Gropius, Jeremy Dellar, Fluxus, William Morris, El Lissitzky and Guerrilla Girls amongst many others. This exhibition claimed to be the first to examine how the production and reception of art has been influenced by left-wing politics in the period from the French Revolution to the present day. The exhibition and the conference thus set out to explore the enduring claims that art practice and art education is, or can be, a social and critical practice that facilitates widening participation and promotes social justice. The conference keynotes by Claire Penketh, Nina Edge, and Julie Allen addressed these issues head on, as did NSEAD President Susan Coles and all of the many and varied papers of the conference delegates.

Penketh's opening keynote drew on her extensive research into disability, special education and art education, exploring the positioning of people considered disabled, and the dominance of medical or professional knowledge over subjective or humanitarian ways of knowing. In her paper reproduced here she utilises discourse analysis to discuss a sample of articles drawn from the pages of this journal over the 
last 30 years. In doing so she extrapolates and applies the rigour of critical analyses developed in gender, class and race politics, to disability studies. Using poignant cases from her research she explores issues of equality, subjectivity and difference, and the potential of arts education to provide a platform for dialogue about these issues.

Nina Edge, the Liverpool-based artist and activist, provided the second keynote of our conference. She is well-known locally for her creation and performance of art on the streets of Liverpool, as well as having an international reputation for her work on the tensions produced in artwork that is rooted in the politics of race. The paper reproduced here recounts and explores her history as a political activist and as an artist who vigorously challenges institutional orthodoxies and inherent racism. In doing so she provides alternative voices and perspectives on the traditionally accepted notions of what it means to be an artist and producer.

The final keynote of the conference was given by Julie Allan (not included in this issue), and drew on her insights into the concept of inclusive education, and its interface with children's rights, particularly as it pertains to arts education. Allan used several case studies of poetry and writing, vividly illustrating the meanings of physical identity, as seen through the eyes of artists and poets who confront these issues on a daily basis.

The remaining articles reproduced in this issue are all invited papers from the 2013 conference. All delegates were given the opportunity to nominate papers that they thought would be appropriate for publication in the journal, in addition to the keynotes. The papers published here therefore reflect the interests of the conference delegates, and in so doing have brought to the journal some who are new to publishing, alongside more established writers.

Nick Addison launches an eloquent yet incisive critique of the notion of predetermined learning outcomes in education, explaining how these distort, homogenise and ultimately reduce the potential richness of subjective and contingent responses to learning situations in art education. However, Addison is careful to point out the laudable and egalitarian provenance of the concept of learning outcomes. As he elucidates, learning outcomes may sit uncomfortably in the arts where subjectivity is encouraged and lauded through constructivist teaching methods, and discusses 
ways in which pedagogies permitting other, more contingent meaning-making imperatives might be accommodated in art educational practices.

Kirsten Adkins' paper is a philosophical discussion about the nature of image-making and representation, contrasting the spectacle of documentary media-generated imagery with that commonly produced in education in the sanitising context of teaching through form and technique. She provides an explanation and a critique for the dominance of these educational regimes, and their failure to exploit the subjective passions of students when encountering highly provocative media images. She calls for a shift away from analysing narrative structures in terms that may be dictated by art historical structuring of images, towards means of developing an understanding of images rooted in the students' own subjective experience.

Richard Hickman's paper examines the experiences of dyslexic beginning teachers of art and design, exploring the relationship of their pedagogical approaches to their dyslexia. He argues that this is especially important for art teachers, since the levels of dyslexia identified in the population of art graduates, from which they are usually drawn, is so high. Hickman describes the noticeably empathetic character of the teaching methods of these students, with their heightened sense of fairness and justice in the classroom; he goes on to explore these students' sense of their own correspondingly heightened visual perceptions, and the role that this might play in their pedagogy. Hickman concludes that all of this has implications for approaches to university teacher training, in which text still dominates.

Jenny Rintoul has similar concerns to Hickman about the dominance of text-based learning in art and design courses, but in her case it is the uneasy relationship of contextual studies in the education of art students. She gives an historical overview of the introduction of theoretical studies into and design education, highlighting the inconsistencies that this has brought about. One of the effects that Rintoul observes is the many varied levels of integration that this has produced in art schools and colleges, and she illustrates the problems associated with too little integration, and contrasts these, surprisingly perhaps, with those associated with too much.

Esther Sayers examines the dialogue that occurs between gallery workshop leaders and young people, and discusses the disjuncture produced by the differentials of cultural familiarity with the culture and implicit assumptions of the art world. Like Adkins she argues for more opportunities to accommodate young people's subjective 
experience, enabling them to bring their own narratives to bear upon works of art, rather than accepting given truths about the nature of art and its value, which she perceives as implicit in many gallery activities. By exploring these underlying cultural values and assumptions Sayers argues that the ultimate goal of widening participation is more likely to be achieved.

Finally, Susan Coles and Elinor Brass discuss a sketchbook project undertaken by teachers as professional development to enable them to re-engage with their own practice as artists. A novel feature of this particular project was that each participant would regularly post their sketchbook to another artist in a pre-established circle, and simultaneously receive one; they would then engage with, and react to, the new work to which they were presented, adding their own contribution before posting on, until the sketchbooks had completed a full cycle of all participants. Coles and Brass argue that this intense and highly engaged collaborative artistic activity often had a very positive impact on the classroom teaching of each of the participants, in terms of both content and pedagogy.

At the time of writing we are preparing for our fifth IJADE conference at Tate Liverpool, on the theme of 'Collaboration', which we hope will produce equally stimulating and insightful contributions, and which will eventually form the content of next year's conference issue of the journal. 